Journal of The Electrochemical Society, 2007, Volume 154, Issue 6, Pages, C318-C325.

Print ISSN: 0013-4651

Online ISSN: $1945-7111$

DOI: $10.1149 / 1.2722535$

http://scitation.aip.org/JES

http://scitation.aip.org/journals/doc/JESOAN-ft/vol_154/iss_6/C318 1.html

(C) The Electrochemical Society, Inc. 2007. All rights reserved. Except as provided under U.S. copyright law, this work may not be reproduced, resold, distributed, or modified without the express permission of The Electrochemical Society (ECS). The archival version of this work was published in Journal of The Electrochemical Society, 2007, Volume, 154, Issue 6, Pages, C318-C325.

\title{
Effects of Particulate Silica Coatings on Localized Corrosion Behavior of AISI 304SS under Atmospheric Corrosion Conditions
}

\author{
Eiji Tada and G. S. Frankel \\ Fontana Corrosion Center, Department of Materials Science and Engineering, The Ohio State University, Columbus, \\ Ohio 43210, USA
}

The effects of a coating of silica particles on the localized corrosion behavior of AISI 304 stainless steel (304SS) during drying of thin electrolyte layers in controlled relative humidity environments were investigated by measurements of the transients of open-circuit potential (OCP) and galvanic current. The silica coatings were composed of spherical silica particles and were deposited on 304SS by cathodic electrophoretic deposition. It was confirmed that the silica layer worked very well as a host layer to soak up electrolyte solutions and that it remained intact under wet and dry conditions. OCP and galvanic current transients indicated that the silica layer affected propagation more than initiation of pitting corrosion. The propagation of pitting corrosion for silica-coated samples was slower than for uncoated 304SS.

Corrosion-resistant alloys (CRAs) covered with rock-dust particulate containing soluble salts and exposed to a hot humid environment might suffer from localized corrosion. ${ }^{1}$ Deliquescence of salts in this particulate layer upon exposure to the high-humidity environment can result in the formation of a thin electrolyte layer, and the particulate layer might act as a crevice former to cause crevice corrosion. Therefore, it is of interest to investigate localized corrosion behavior of CRAs under thin layers of electrolyte-containing particulate.

We have employed electrophoretic deposition (EPD) to create a silica coating on stainless steel, which can simulate rock dust. ${ }^{2}$ It is well known that EPD is a very useful technique to deposit layers of ceramic particles on metal surfaces with thickness on the order of micrometers to millimeters. ${ }^{3-5}$ Furthermore, because the thickness of the ceramic layers can be controlled easily by changing applied voltage or deposition time, EPD can be utilized to create simulated particulate layers on CRAs in a reproducible and controllable fashion. In a previous study, ${ }^{2}$ the formation of silica layers on 304SS by cathodic EPD was described and the effects of the silica layer on localized corrosion behavior in a stagnant bulk solution were investigated. It was concluded that the EPD silica layers did not affect the anodic reactions; passive current densities and breakdown potentials were not dependent on the presence or thickness of the silica coating. The silica coatings did affect the cathodic process; the limiting current density due to the oxygen reduction reaction (ORR) decreased with increasing silica layer thickness. However, the electrochemical behavior of the silica-coated 304SS was only studied in bulk solutions and not in an atmospheric corrosion environment.

The purpose of this study is to investigate localized corrosion behavior of silica-coated 304SS under atmospheric corrosion conditions and to clarify the effect of the silica layer on 
initiation and propagation of pitting corrosion. In this study, we measured OCP and galvanic current transients for silica-coated 304SS during drying of some salt solutions under controlled relative humidity $(\mathrm{RH})$ conditions.

\section{Experimental}

Figure 1a shows the electrochemical setup for the atmospheric corrosion experiments employed in this study. A plastic container with a lid was used as a chamber in which the RH was controlled using saturated $\mathrm{LiCl}$ or $\mathrm{MgCl}_{2}$ solutions at the bottom of the chamber. As seen in Fig. 1a, sample holders were used to fix the samples horizontally. Furthermore, humidity and temperature sensors were placed in the chamber to monitor RH and temperature $(\mathrm{T})$.

The atmospheric corrosion behavior of silica-coated samples was investigated by monitoring open-circuit potential (OCP) and galvanic current $\left(i_{\mathrm{g}}\right)$ transients during drying of a thin electrolyte layer. Figure $1 \mathrm{~b}$ shows a schematic drawing of a sample for OCP measurements. An AISI 304 stainless steel electrode (304SS, ca. $1 \times 1 \mathrm{~cm}$ ) was embedded in epoxy resin. A hole approximately $3 \mathrm{~mm}$ in diameter was drilled in the epoxy resin near the plate. Before OCP measurements, agar gel containing $\mathrm{KCl}$ was filled in the hole to achieve an ionic contact between the plate and the reference electrode, according to the procedure described by Vera Cruz et al. Figure $1 \mathrm{c}$ shows a schematic drawing of a sample for galvanic current $\left(i_{\mathrm{g}}\right)$ measurements. Two identical 304SS electrodes (ca. $1 \mathrm{~cm} \times 0.2 \mathrm{~mm}$ ) were embedded in parallel in epoxy resin separated by a $0.23 \mathrm{~mm}$ thick polystyrene sheet. Both the samples for OCP and $i_{\mathrm{g}}$ measurements were polished with abrasive papers to 1200 grit and cleaned ultrasonically with ethyl alcohol (EtOH). Then, cathodic EPD of silica was conducted on the surface of 304SS. The procedure to create the silica layers on 304SS was described in detail in a previous paper. ${ }^{2}$ After depositing the silica coating, the samples were stored in a desiccator until just before the atmospheric corrosion experiments.

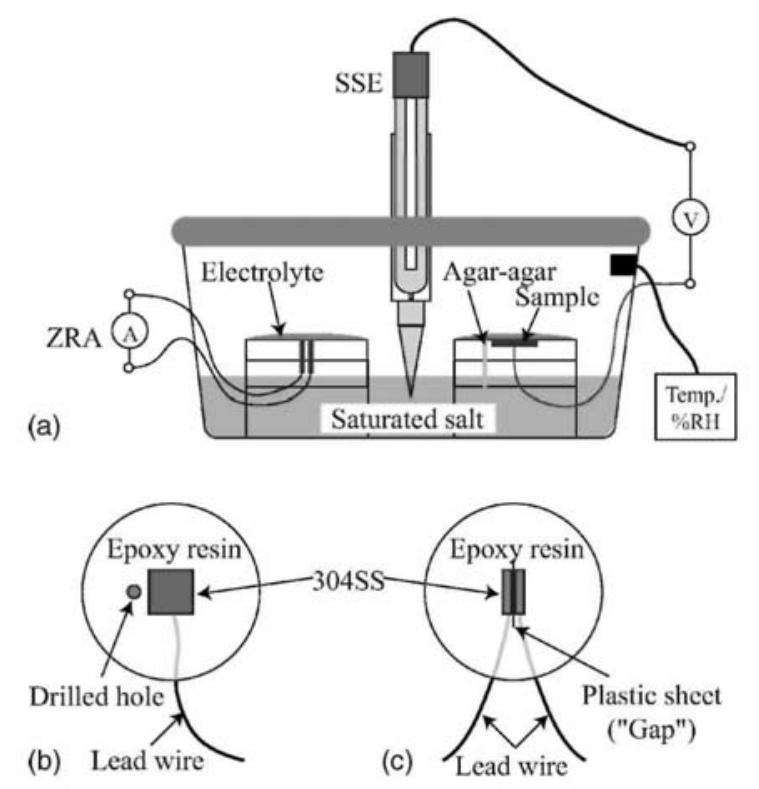

Figure 1. Experimental setup for atmospheric corrosion experiments: (a) chamber, (b) sample for OCP measurement, and (c) sample for $i_{\mathrm{g}}$ measurement where two 304SS electrodes are separated by a plastic sheet. 
The test electrolyte solutions applied on the samples were either $0.5 \mathrm{M} \mathrm{NaCl}$ or $x \mathrm{M}$ $\mathrm{MgCl}_{2}(x=0.05-3)$. For the OCP and $i_{\mathrm{g}}$ measurements, a silica-coated sample was set horizontally on one of the holders in the chamber and then a certain amount of $\mathrm{NaCl}$ or $\mathrm{MgCl}_{2}$ electrolyte was applied to the surface using a pipetter. The plastic pipetter tip was used to spread the electrolyte over the entire sample surface, including the epoxy resin, being careful not to touch the sample surface with the tip. For all the atmospheric corrosion experiments in this study, the initial thickness of the thin electrolyte layer was $500 \mu \mathrm{m}$, assuming a layer of uniform thickness. OCP transients were measured during drying of the thin electrolyte layer using an electrometer in a potentiostat (model 263A, PAR) and a commercial reference electrode, as shown in Fig. 1a. The reference electrode connected with a Luggin capillary was an $\mathrm{Ag} / \mathrm{AgCl}$ electrode in a $4 \mathrm{M} \mathrm{KCl}$ solution [SSE, $\mathrm{E}_{\mathrm{SSE}}=0.197 \mathrm{~V}$ vs standard hydrogen electrode (SHE)]. In this paper, all potential values are referred to this reference electrode. For $i_{\mathrm{g}}$ measurements, a sample like the one shown in Fig. 1c was placed in the chamber and the galvanic current flowing between the pair of stainless steel electrodes was measured during drying of the thin electrolyte layer by using the potentiostat as a zero-resistance ammeter (ZRA). ${ }^{7}$

After the experiments the samples were analyzed for any evidence of crevice corrosion. If crevice corrosion was observed, the results were discarded.

\section{Results}

Silica layer deposited by EPD. - Because the silica layer deposited on 304SS is intended to be used as a simulated particulate layer that is a host for electrolytes under atmospheric corrosion conditions, permeability of electrolytes into the silica layer is a critical issue. The permeability of electrolytes in a particulate silica layer depends on the hydrophilicity of the silica and the packing structure of the silica layer. A silica coating was deposited on a partially immersed sample for $5 \mathrm{~s}$ to investigate the packing structure of the silica layer. As shown in Fig. $2 \mathrm{a}$, the silica layer formed on 304SS was quite smooth and homogeneous. The high magnification micrograph in Fig. $2 \mathrm{~b}$ reveals that the silica layer was composed of a vast number of spherical silica particles about $350 \mathrm{~nm}$ in diameter packed densely. Figure $2 \mathrm{c}$ shows the top edge of the silica coating where the sample intersected the water line of the EPD suspension. The coating is thinner in this region but the packing structure appears to be the same as the thick region shown in Fig. 2a. The previous paper showed a linear relationship between silica layer thickness and deposition time. ${ }^{2}$ A new batch of silica particles was used in this study and Fig. 3 shows that a linear relationship was also observed with the second batch of particles. A leastsquares fit results in the following relationship

$$
d=0.57 t
$$

where $d$ and $t$ are the silica layer thickness $(\mu \mathrm{m})$ and deposition time (s), respectively. The maximum silica layer thickness obtained in this study was about $60 \mu \mathrm{m}$. Thicker layers peeled off the substrate after deposition due to shrinkage during evaporation of the EtOH in the EPD suspension. Because the silica layer thickness was proportional to the deposition time at a constant applied voltage, it is reasonable that the packing structure was independent of the thickness of the silica layer, as shown in Fig. 2a and c.

As shown in Fig. 2b, there is space around the spherical silica particles through which an electrolyte can permeate. When a drop of water was put at the edge of a silica layer, the drop was 
absorbed rapidly in the silica layer, and almost the whole surface of the silica layer became wet after a while because of capillary action. Contact-angle measurements were not made, but the silica layer appeared to be totally wetted with a contact angle of almost $0^{\circ}$. The silica layers deposited by EPD in this study were hydrophilic and the interstitial spaces between the silica particles facilitated absorption of liquid water. Furthermore, the silica layers remained intact when wetted and then dried with air. These results suggest that the silica layers deposited by cathodic EPD can act as a humectant and that the layer can be used as a suitable host layer for a thin electrolyte layer under atmospheric wet/dry conditions.

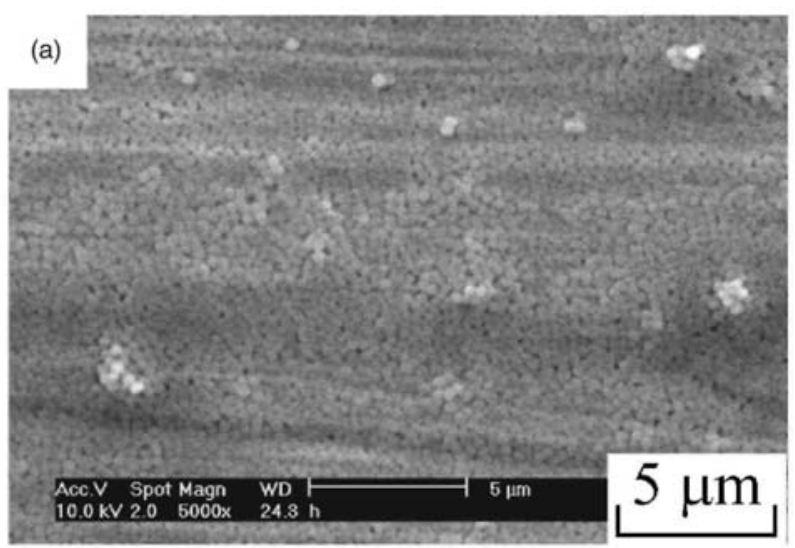

(b)
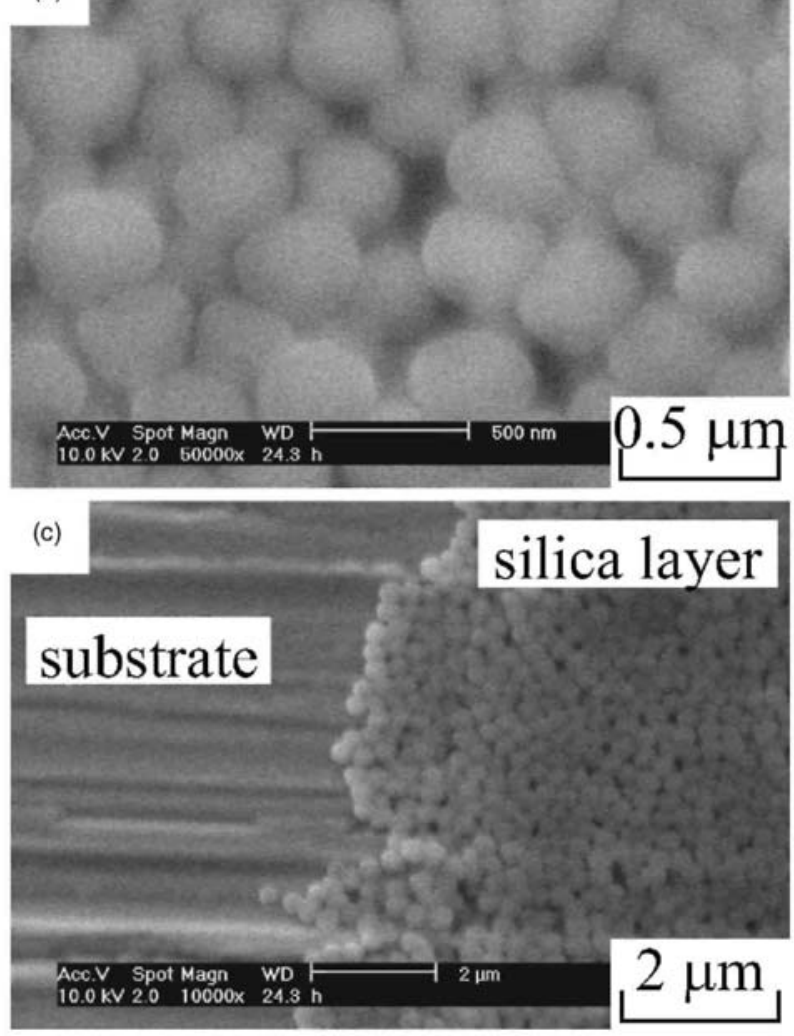

Figure 2. Scanning electron micrograph of the surface of a silica-coated 304SS; (a) low magnification, (b) high magnification, and (c) around a water line region of the layer. The silica layer was deposited for $5 \mathrm{~s}$ on the 304SS substrate. 
OCP transients during drying of $\mathrm{NaCl}$ solution. - Figure 4 shows OCP transients for silica-coated and uncoated samples. For these experiments, the RH in the chamber was controlled by a large reservoir of saturated $\mathrm{MgCl}_{2}$ solution at the bottom of the chamber and the RH was measured to be in the range of $37-40 \%$. A layer of $0.5 \mathrm{M} \mathrm{NaCl}$ with initial thickness of $500 \mu \mathrm{m}$ was placed on the sample prior to sealing the chamber. The RH in equilibrium with 0.5 $\mathrm{M} \mathrm{NaCl}$ is above $95 \%$, so the thin $\mathrm{NaCl}$ layer released moisture into the air in an attempt to equilibrate with the lower $\mathrm{RH}$ set by the saturated $\mathrm{MgCl}_{2}$ solution. The $\mathrm{NaCl}$ concentration in the layer increased with time during drying. The estimated thicknesses of the silica layers on the samples were about $6 \mu \mathrm{m}(10 \mathrm{~s}), 17 \mu \mathrm{m}(30 \mathrm{~s})$, and $34 \mu \mathrm{m}(60 \mathrm{~s})$, which are all much less than the initial electrolyte layer thickness.

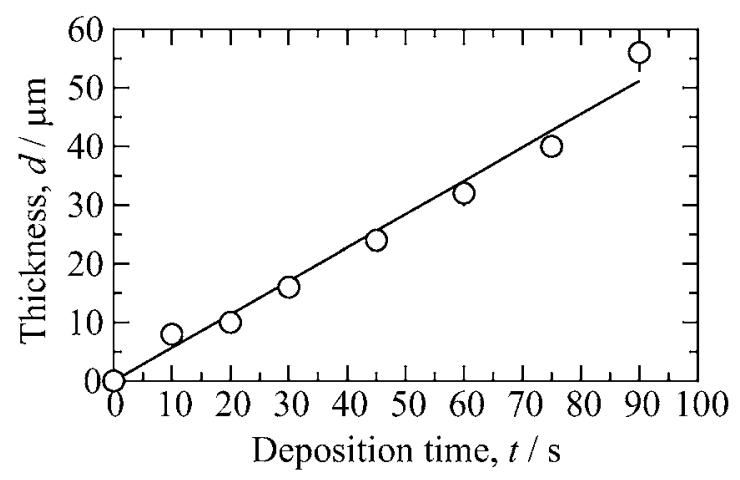

Figure 3. Change in the thickness of a silica layer with deposition time.

The OCP transients in Fig. 4 can be divided into four regions. A transient period was observed during the first 30-45 min of immersion. Then, the OCP was almost stable for several hours and the OCP values of all samples were almost constant during the period and close to -0.1 V. After 5-6 h, the OCP tended to shift gradually in the noble direction with time. Finally, after 6-7 h, the transients all exhibited large fluctuations. The critical humidity in equilibrium with saturated $\mathrm{NaCl}$ is about $75 \%,{ }^{8}$ so the $\mathrm{NaCl}$ solution eventually dried up completely in the chamber with lower RH. The resistance between the end of the agar-filled hole and the sample increased sharply when the electrolyte layer dried completely, and the measured OCP became very noisy, as is seen in Fig. 4, after 6-7 h. It might be expected that it should take longer for evaporation of an electrolyte layer on a sample with thicker silica layer, because the silica layer can retain the electrolyte by capillary action. Figure 4 shows no correlation between drying time and silica layer thickness, perhaps because the silica layer thickness was much smaller than the initial thickness of the electrolyte and most of the drying time was associated with evaporation of the electrolyte on top of the silica layer. The difference in drying times might reflect more strongly the variation in initial electrolyte layer thickness, and the expected reduction in drying rate associated with the capillary action in the silica layers seems to be small in comparison.

There was no evidence for the initiation of localized corrosion in the form of a sharp decrease in OCP for any of the samples, and observation of the uncoated 304SS sample revealed no indication of localized attack. The solubility of $\mathrm{NaCl}$ in water at $20^{\circ} \mathrm{C}$ is about $5.4 \mathrm{M}$, which is less than the critical concentration of $\mathrm{Cl}$ - for the initiation of pitting corrosion on 304SS. ${ }^{6}$ Note that this conclusion is only valid for exposure times on the order of hours; it could be possible for pitting to initiate at $\mathrm{OCP}$ during long exposures to lower chloride content environments. 


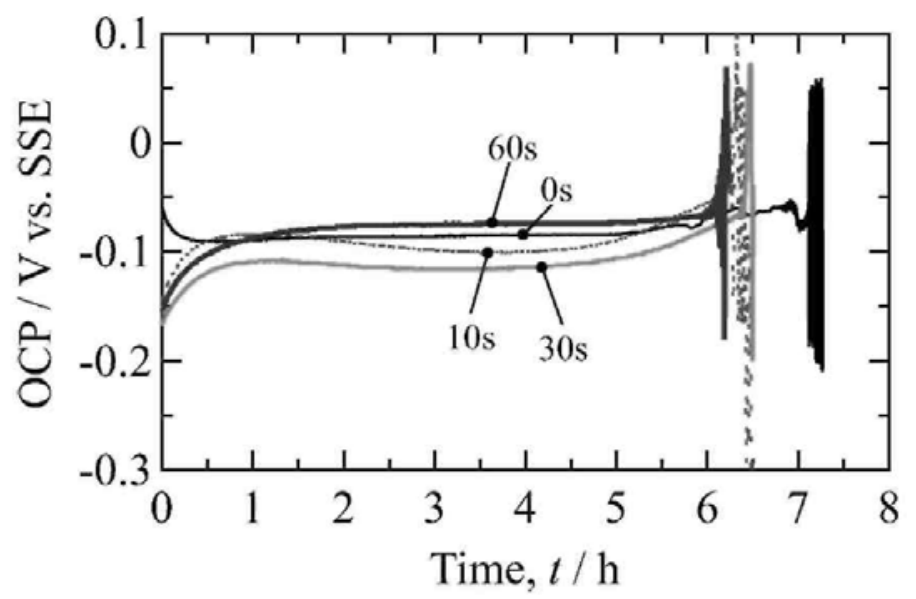

Figure 4. OCP transients for silica-coated 304SS with varying thickness during drying of $0.5 \mathrm{M} \mathrm{NaCl}$ under a saturated $\mathrm{MgCl}_{2}$ environment. The time shown in the figure denotes the deposition time of a silica layer on 304SS.
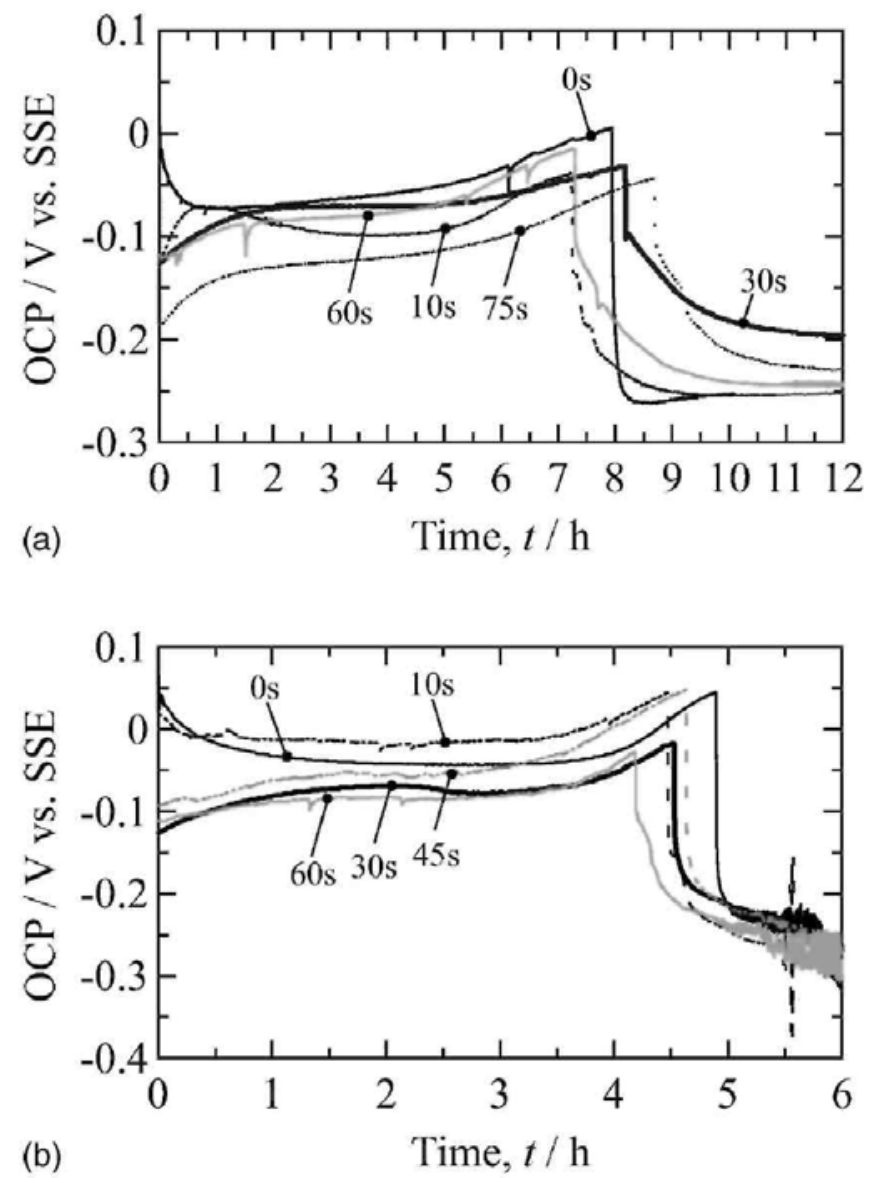

Figure 5. OCP transients for silica-coated 304SS with varying thickness during drying of $0.5 \mathrm{M} \mathrm{MgCl}_{2}$ under saturated (a) $\mathrm{MgCl}_{2}$ and (b) $\mathrm{LiCl}$ environments. The time shown in the figure denotes the deposition time of a silica layer on $304 \mathrm{SS}$. 
OCP transients during drying of $\mathrm{MgCl}_{2}$ solution. - To investigate localized corrosion behavior of 304SS under a thin layer of electrolyte, a solution with concentration higher than that of saturated $\mathrm{NaCl}$ is needed. Therefore, OCP transients were measured during drying of a layer of initial concentration $0.5 \mathrm{M} \mathrm{MgCl}_{2}$, which has a saturation concentration of $9.92 \mathrm{M} \mathrm{Cl}^{-}{ }^{9}$ If the critical concentration for pit initiation of 304SS at room temperature is below this value, it is expected that pitting corrosion will initiate when the concentration of the $\mathrm{MgCl}_{2}$ layer reaches the critical value in the course of the drying process.

Figure 5a shows OCP transients for silica-coated and uncoated samples during drying of an electrolyte layer initially $500 \mu \mathrm{m}$ thick and of concentration $0.5 \mathrm{M} \mathrm{MgCl}_{2}$ in an environment with $\mathrm{RH}$ set by a saturated $\mathrm{MgCl}_{2}$ solution. The estimated thicknesses of silica layers on the samples were about $6 \mu \mathrm{m}(10 \mathrm{~s}), 17 \mu \mathrm{m}(30 \mathrm{~s}), 34 \mu \mathrm{m}(60 \mathrm{~s})$, and $43 \mu \mathrm{m}(75 \mathrm{~s})$. In this experiment, the electrolyte layer put on the sample gets thinner during drying but stops decreasing in thickness when the concentration of the electrolyte layer reaches saturation. As shown in Fig. 5a, there was an initial transient period followed by a period of constant potential around $-0.1 \mathrm{~V}$ and then a gradual increase in potential. However, at about 7-9 h, prior to the onset of fluctuations attributed to drying of the $\mathrm{MgCl}_{2}$ layer, all samples exhibited a sharp drop in OCP. This activation of the electrode is associated with the initiation of pitting corrosion, as has been shown by Tsutsumi et al. ${ }^{9}$ As described below, evidence of localized corrosion was observed during examination of the samples after the experiment. Following the initial sharp drop in OCP, the potential gradually dropped by hundreds of $\mathrm{mV}$ to the end of the $12 \mathrm{~h}$ period of observation. The potential observed following the sharp drop is representative of the growth stage of pitting corrosion during drying of the $\mathrm{MgCl}_{2}$ layer.

Prior to the onset of pitting, the behaviors of the silica-coated and uncoated samples were similar to that in the $\mathrm{NaCl}$ solution. There was also no correlation between silica-layer thickness and time to initiation, again probably a result of a variation in initial layer thickness changing the time to achieve the critical chloride concentration. However, after pitting corrosion initiated, the OCP decay transients for the silica-coated samples were much slower than for the uncoated sample. For the uncoated sample, the OCP dropped abruptly by about $250 \mathrm{mV}$ and then remained relatively constant. In contrast, the OCP of the silica-coated sample decreased by a smaller amount when pitting initiated and then decayed gradually over a period of hours to more active values. These results suggest that the silica layer might not influence pit initiation but might retard pit growth.

Similar experiments were performed to measure OCP transients for silica-coated and uncoated samples during drying of an electrolyte layer initially $500 \mu \mathrm{m}$ thick and of concentration $0.5 \mathrm{M} \mathrm{MgCl}_{2}$ in an environment with $\mathrm{RH}$ set by a saturated $\mathrm{LiCl}$ solution. The critical $\mathrm{RH}$ in equilibrium with saturated $\mathrm{LiCl}$ is lower yet, $11 \%$ at $20{ }^{\circ} \mathrm{C}$. The estimated thicknesses of the silica layers on the samples were about $6 \mu \mathrm{m}(10 \mathrm{~s}), 17 \mu \mathrm{m}(30 \mathrm{~s}), 27 \mu \mathrm{m}$ (45 $\mathrm{s})$, and $34 \mu \mathrm{m}(60 \mathrm{~s})$. In this experiment, the samples should dry up completely, as was observed above for the $\mathrm{NaCl}$ solution in the $40 \% \mathrm{RH}$ environment; because the critical $\mathrm{RH}$ of $\mathrm{LiCl}(11 \%$ $\mathrm{RH})$ is much lower than that of $\mathrm{MgCl}_{2}$. However, the $\mathrm{MgCl}_{2}$ concentration should reach a critical value for pit initiation before drying. The results are shown in Fig. 5b. Like the OCP transients shown in Fig. 4 and 5a, the OCP transients before the onset of pitting corrosion are quite similar to one another and similar in form to the other conditions. However, the time for pit initiation was shorter than in the higher $\mathrm{RH}$ environment created by saturated $\mathrm{MgCl}_{2}$ solution, because the lower RH environment increased the rate of drying. An increase in drying rate with decreasing ambient RH is expected if the rate of drying is controlled by transport of water vapor across a 
boundary layer from the higher RH next to the sample to the lower bulk RH. As observed in the higher humidity environment, the potential drop was largest for the uncoated sample and the silica-coated samples exhibited a potential decay after pit initiation. Fluctuations associated with complete drying of the electrolyte occurred during the pitting propagation stage.

The effect of initial electrolyte concentration on OCP behavior was investigated with silica-coated and uncoated samples in an environment with $\mathrm{RH}$ set by saturated $\mathrm{MgCl}_{2}$ solution. The silica coating was formed during a $30 \mathrm{~s}$ deposition, and the thickness is estimated to be about $17 \mu \mathrm{m}$ from Eq. 1. The initial electrolyte concentration was in the range of $0.05-3 \mathrm{M}$ and the initial thickness of the electrolyte layer on the samples was the same as the other experiments, about $500 \mu \mathrm{m}$. The OCP transients for the uncoated and silica-coated samples are shown in Fig. 6. The OCP transients have a similar form to those shown earlier. The transients for the uncoated samples (Fig. 6a) show a plateau, then a sharp drop followed by a constant value, and the coated samples (Fig. 6b) exhibit a smaller drop and slower potential decay. For a low initial electrolyte concentration, the time to achieve the critical concentration for pitting initiation should be longer and the thickness of the electrolyte layer when pitting corrosion is initiated should be less. However, for both the uncoated and coated samples, no clear relationship between time for initiation of pitting corrosion and initial electrolyte concentration was observed, except for the case of $3 \mathrm{M}$ initial concentration. This result could be related to the higher evaporation rate for electrolytes of lower concentration due to differences in their equilibrium vapor pressures. For both the uncoated and coated samples with $3 \mathrm{M}$ initial concentration, pitting corrosion initiated relatively rapidly. For the silica-coated sample with $3 \mathrm{M}$ electrolyte, some spikes due to metastable pitting occurred before the abrupt decrease associated with stable pitting after about 1 h. Pitting corrosion initiated almost immediately after the $3 \mathrm{M}$ solution was put on the uncoated sample. Therefore, it appears that the silica coating inhibited pitting corrosion to a certain extent in the $3 \mathrm{M} \mathrm{MgCl}_{2}$ solution.

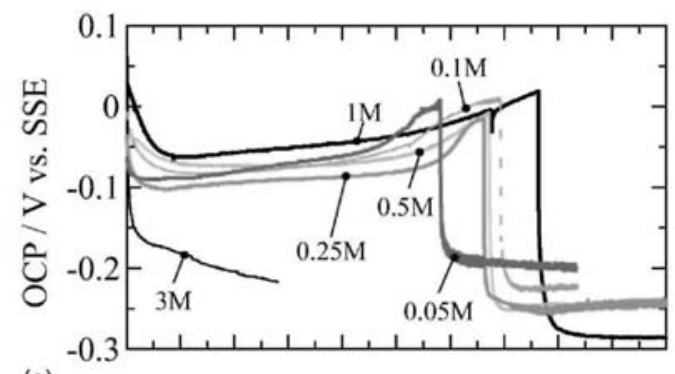

(a)

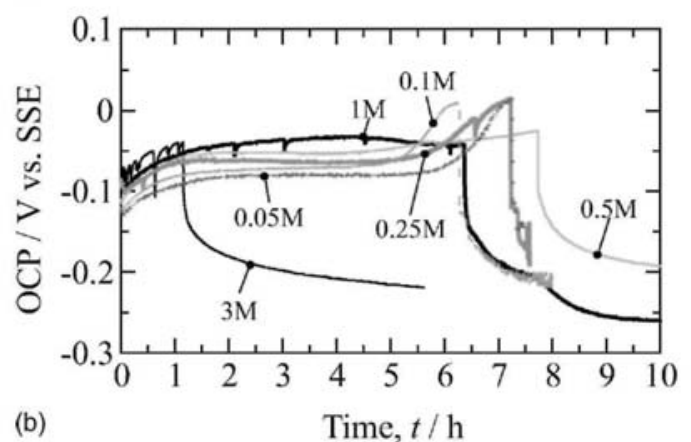

Figure 6. OCP transients for (a) uncoated and (b) silica-coated 304SS during drying of $x \mathrm{M} \mathrm{MgCl}_{2}(x=0.05$ to 3$)$ under a saturated $\mathrm{MgCl}_{2}$ environment. The deposition time of a silica layer on a sample was $30 \mathrm{~s}$. 
Galvanic current transients during drying of $\mathrm{MgCl}_{2}$ solution. - Initiation and propagation of pitting corrosion under atmospheric corrosion environments were investigated by measuring galvanic current $\left(i_{\mathrm{g}}\right)$ between combinations of silica-coated and uncoated samples during drying of $\mathrm{MgCl}_{2}$. The time described in the following figures denotes the deposition time for the silica layers on the surface of 304SS. For example, $10 \mathrm{~s}-30 \mathrm{~s}$ denotes that one of the electrodes in Fig. 1c (left side) was coated with a silica layer deposited for $10 \mathrm{~s}$ and the other one (right side) for 30 s.

Figure 7a shows $i_{\mathrm{g}}$ transients during drying of an electrolyte layer initially $500 \mu \mathrm{m}$ thick and of concentration $0.5 \mathrm{M} \mathrm{MgCl}_{2}$ in an environment with $\mathrm{RH}$ controlled by saturated $\mathrm{LiCl}$ solution, so the electrolyte put on the sample dried out completely during the experiments. The estimated thicknesses of silica layers on the samples were about $6 \mu \mathrm{m}(10 \mathrm{~s})$ and $17 \mu \mathrm{m}(30 \mathrm{~s})$. All transients in this figure exhibited almost constant ig initially, followed by a gradual change in the negative direction. Because a similar change of $i_{\mathrm{g}}$ was also observed on the uncoated sample, this trend was not caused by the silica layer but by the electrochemical reactions taking place during the drying process. After about $5 \mathrm{~h}, i_{\mathrm{g}}$ changed abruptly in the negative direction for all samples, indicating that pitting corrosion occurred and that the pitting was on the uncoated side of the $0 \mathrm{~s}-10 \mathrm{~s}$ pair. The time for initiation of pitting corrosion was in the range of 4.7-5 h, which is in good agreement with the results seen in the OCP transients in Fig. 5b, and no clear effect of silica-layer thickness on this time was observed, as was the case for the OCP measurements. The $i_{\mathrm{g}}$ transient for the $0 \mathrm{~s}-0 \mathrm{~s}$ sample abruptly increased in the negative direction, reached a peak value, and then rapidly decayed to almost zero current. This sudden decrease in current might be related to complete drying of the layer, which was observed in the same time period in the OCP experiments. In contrast, the $i_{\mathrm{g}}$ transient for the silica-coated samples exhibited a slow decay after the peak value and took longer to reach zero. This might indicate that drying of the coated samples took longer under the conditions of this experiment.
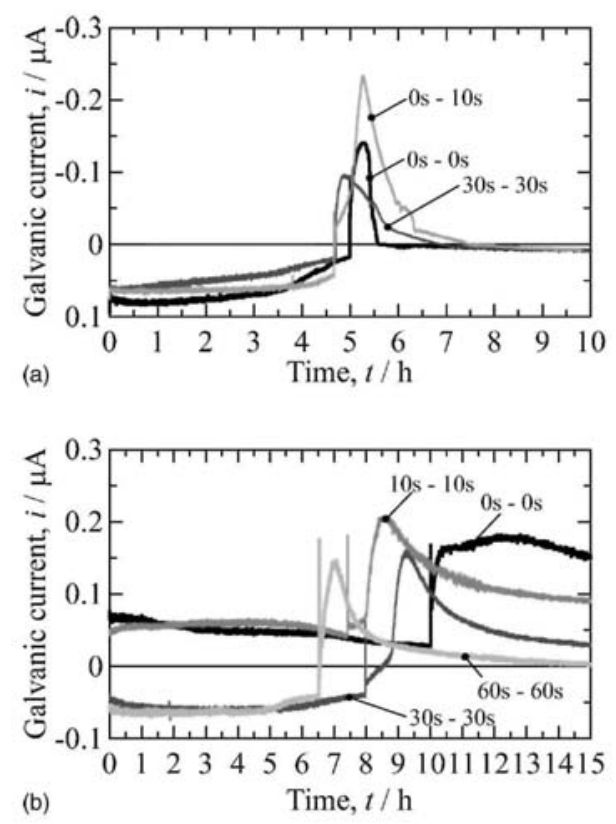

Figure 7. Galvanic current transients for 304SS electrodes with and without a silica layer during drying of $0.5 \mathrm{M}$ $\mathrm{MgCl}_{2}$ under saturated (a) $\mathrm{LiCl}$ and (b) $\mathrm{MgCl}_{2}$ environments. The time shown in the figure denotes the silica layer deposition time for each electrode surface of the samples. 
Figure $7 \mathrm{~b}$ shows $i_{\mathrm{g}}$ transients during drying of an electrolyte layer initially $500 \mu \mathrm{m}$ thick and of concentration $0.5 \mathrm{M} \mathrm{MgCl}_{2}$ in an environment with $\mathrm{RH}$ controlled by saturated $\mathrm{MgCl}_{2}$ solution, so that complete drying should not occur and the layer should approach the $\mathrm{MgCl}_{2}$ saturation concentration. In this experiment, both electrodes were coated with a silica layer of the same thickness. The estimated thicknesses of silica layers on the samples were about $6 \mu \mathrm{m}(10$ $\mathrm{s}), 17 \mu \mathrm{m}(30 \mathrm{~s})$, and $34 \mu \mathrm{m}(60 \mathrm{~s})$. As shown in Fig. 7b, pitting corrosion took place on all the samples tested 6.5-10 $\mathrm{h}$ after immersion in $0.5 \mathrm{M} \mathrm{MgCl}_{2}$. The time for initiation of pitting corrosion in this environment was consistent with the results of the OCP transients in Fig. 5a. The polarity of the transients was adjusted so that the transient was in the positive direction; because the samples were symmetric, assignment is arbitrary. Every sample exhibited a very sharp spike in current, followed by a drop and then a slower increase to a peak current value. The sharp spikes appear to be related to the pit initiation event. The current decreased over long periods following the second peak, and the rate of decrease was much slower for the uncoated 0 s-0 s sample.

\section{Discussion}

As described above, the silica layer prepared in this study absorbed electrolytes very well. This is attributed to the hydrophilic characteristics of silica and permeation of electrolytes through the spacing around the silica particles in the silica layer. In addition, the silica layer did not delaminate from the substrate during atmospheric corrosion experiments. Therefore, it can be concluded that the silica layer deposited by EPD could be an appropriate model to represent thin particulate layers that might form in dusty environments.

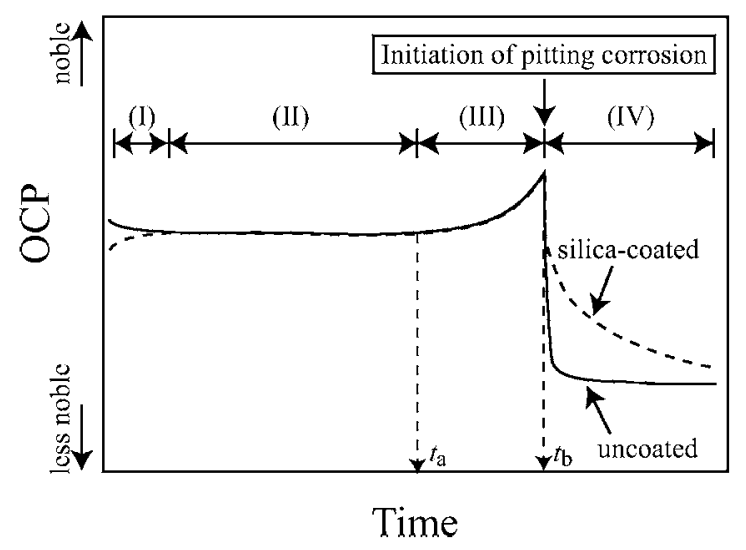

Figure 8. Schematic diagram of OCP transients for silica-coated and uncoated samples during drying of $\mathrm{MgCl}_{2}$ electrolytes.

The OCP transients for 304SS during drying of $0.5 \mathrm{M} \mathrm{NaCl}$ or $\mathrm{MgCl}_{2}$ can be divided into three regions. If pitting corrosion occurred, a fourth region can be added in the OCP transient, as shown in Fig. 5 and 6. Therefore, the OCP transients for silica-coated and uncoated samples can be described as shown in Fig. 8. In region I, the OCP changed toward a stable value as the airformed oxide film was altered after immersion in the electrolyte. In region II, the OCP was almost constant, although the thickness of the electrolyte decreased and the concentration increased. In region III, the OCP gradually changed in the noble direction, and pitting corrosion 
occurred in region IV. The times when regions III and IV started are defined in Fig. 8 as $t_{\mathrm{a}}$ and $t_{\mathrm{b}}$, respectively. Table I shows the values of $t_{\mathrm{a}}$ and $t_{\mathrm{b}}$ obtained from OCP transients for uncoated and silica-coated samples during drying of $\mathrm{MgCl}_{2}$ under saturated $\mathrm{MgCl}_{2}$ and $\mathrm{LiCl}$ environments in Fig. 5. Because the $t_{\mathrm{a}}$ and $t_{\mathrm{b}}$ under both drying environments did not depend strongly on the silica layer thickness or deposition time, it is reasonable to consider the average values of $t_{\mathrm{a}}$ and $t_{\mathrm{b}}$, as shown in Table I, to estimate the thickness of the electrolyte layer when regions III and IV started. Tsutsumi et al. investigated the OCP behavior of 304SS during drying of $\mathrm{MgCl}_{2}$ and reported that the critical concentration of $\mathrm{Cl}$ - for initiation of pitting corrosion on 304SS is around $6 \mathrm{M} .{ }^{9}$ Assuming that pitting corrosion initiated on all samples regardless of silica coating when the Cl-concentration reached $6 \mathrm{M}$ and an initial electrolyte layer thickness of $500 \mu \mathrm{m}$, the electrolyte layer thickness when region IV started should be $83.3 \mu \mathrm{m}$ in both drying environments. Assuming further a linear drying rate (which might be a poor assumption given the differences observed in Fig. 6 for different initial concentrations), the estimated electrolyte layer thickness when region III started was 213 and $205 \mu \mathrm{m}$ for the $\mathrm{MgCl}_{2}$ and $\mathrm{LiCl}$ environments, respectively. The electrolyte thickness would be somewhat greater than this due to the volume taken up by the silica spheres. However, the layers contain considerable open pore space.

Table I . $t_{\mathrm{a}}$ and $t_{\mathrm{b}}$ obtained from OCP transients for silica-coated and uncoated samples shown in Fig. 6 and $7 . t_{\mathrm{a}}$ and $t_{\mathrm{b}}$ denote the times described in Fig. 8 .

\begin{tabular}{lcccc} 
Drying environments & Deposition time $(\mathrm{s})$ & $t_{\mathrm{a}}(\mathrm{h})$ & $t_{\mathrm{b}}(\mathrm{h})$ & $t_{\mathrm{a}} / t_{\mathrm{b}}(\%)$ \\
\hline Saturated $\mathrm{MgCl}_{2}$ & 0 & 5.43 & 7.94 & 68.4 \\
& 10 & 5.12 & 7.23 & 70.8 \\
& 30 & 5.66 & 8.17 & 69.3 \\
& 60 & 4.99 & 7.29 & 68.5 \\
& 75 & 5.88 & 8.68 & 67.7 \\
& Average & 5.42 & 7.86 & 68.9 \\
Saturated LiCl & & & & \\
& 0 & 3.58 & 4.89 & 73.2 \\
& 10 & 3.29 & 4.47 & 73.2 \\
& 30 & 3.15 & 4.53 & 69.6 \\
& 45 & 3.10 & 4.63 & 67.1 \\
& 60 & 2.93 & 4.19 & 70.0 \\
& Average & 3.21 & 4.54 & 70.7
\end{tabular}

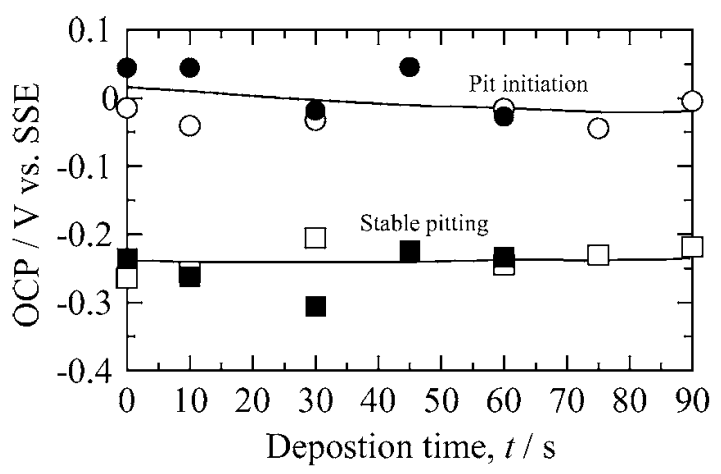

Figure 9. OCP for silica-coated and uncoated samples obtained before and after initiation of pitting corrosion as a function of the deposition time. Open and solid symbols denote the results under saturated $\mathrm{MgCl}_{2}$ and $\mathrm{LiCl}$ environments, respectively. 
Table II. $t_{\mathrm{a}}$ and $t_{\mathrm{b}}$ obtained from OCP transients for uncoated and silica-coated samples shown in Fig. 8 and 9. $t_{\mathrm{a}}$ and $t_{\mathrm{b}}$ denote the times described in Fig. 8.

\begin{tabular}{lcccc} 
Samples & Concentration $(\mathrm{M})$ & $t_{\mathrm{a}}(\mathrm{h})$ & $t_{\mathrm{b}}(\mathrm{h})$ & $t_{\mathrm{a}} / t_{\mathrm{b}}(\%)$ \\
\hline Uncoated 304SS & 0.05 & 4.39 & 5.82 & 75.5 \\
& 0.1 & 4.85 & 6.93 & 70.0 \\
& 0.25 & 5.00 & 6.62 & 75.5 \\
& 0.5 & 4.62 & 6.72 & 68.8 \\
& 1 & 5.33 & 7.63 & 69.8 \\
Silica-coated 304SS & 3 & - & 0.03 & - \\
& & & & \\
& 0.05 & 5.38 & 7.25 & 74.1 \\
& 0.1 & 4.62 & 6.72 & 73.6 \\
& 0.5 & 5.02 & 7.23 & 69.5 \\
& 1 & 5.30 & 7.73 & 69.5 \\
& 3 & - & 6.36 & - \\
& & - & 1.19 & -
\end{tabular}

This analysis suggests that the ennoblement of OCP in region III started when the electrolyte layer thickness became thinner than approximately $200 \mu \mathrm{m}$. Furthermore, because the electrolyte layer thickness in region II was more than $200 \mu \mathrm{m}$, the electrochemical reactions taking place in region II were similar to those in a bulk electrolyte. As discussed in our previous paper, ${ }^{2}$ for silica-coated 304SS exposed at OCP to a stagnant air-exposed dilute chloride solution, the ORR is under activation control and the rate-determining step is the anodic reaction, i.e., passive dissolution. The constant OCP in region II suggests that the passive dissolution is at steady state for thick electrolyte layers. The OCP moved toward the noble direction in region III as the electrolyte layer thickness decreased below $200 \mu \mathrm{m}$. The situation during drying is quite complex. As the water evaporates from the thin electrolyte layer, the chloride concentration increases, the oxygen concentration decreases, the viscosity and diffusivity decrease, the passive current density increases, and the diffusion length decreases after the layer thickness decreases below the diffusion layer determined by natural convection. These factors affect the cathodic and anodic kinetics and thus the mixed corrosion potential. The increase in OCP in region III indicates that the dominant factor is the decrease in diffusion layer thickness as the other factors would tend to cause an increase in OCP.

The solution layer consists of two parts: the solution in the open space in the silica layer and the solution above the silica layer. The extent of open space depends on the particle packing and defects in the layer. The images in Fig. 2 suggest that the EPD silica particles are closepacked in regions, but that defects in the packing result in additional open space. For a closepacked structure, the open space is $26 \%$ of the volume. Ignoring the defects, a $43 \mu \mathrm{m}$ thick silica layer would have $11 \mu \mathrm{m}$ of equivalent open space. Therefore, an $83 \mu \mathrm{m}$ solution layer at the initiation of pitting would actually be $72 \mu \mathrm{m}$ of solution on top of the saturated porous silica layer.

As shown in Fig. 6, the OCP behavior after the initiation of pitting corrosion was significantly different for silica-coated and uncoated samples; the OCP decreased much faster for uncoated samples. The OCP values just before initiation of pitting corrosion and the stable potentials during pitting corrosion were obtained from Fig. 5 and are plotted against the silica layer deposition time in Fig. 9. Open and solid symbols denote the results from OCP transients in saturated $\mathrm{MgCl}_{2}$ and $\mathrm{LiCl}$ environments, respectively. The drying rate should be higher in the 
saturated $\mathrm{LiCl}$ environment because of its lower critical humidity. The OCP values just before pit initiation correspond to the pitting potentials of freely corroding samples during drying of $0.5 \mathrm{M}$ $\mathrm{MgCl}_{2}$. As shown in Fig. 9, the pitting potential seems to be independent of the deposition time and the drying rate. This result suggests that the pitting potential should be associated with the Cl- concentration of the electrolyte when pitting corrosion is initiated. In the course of drying of the electrolyte, the decrease in the thickness of the electrolyte and the increase in concentration of the electrolyte layer occur simultaneously. All pits upon initiation can be considered to be metastable pits that either repassivate or transform to a stable pit. ${ }^{10}$ Metastable pit initiation on 304SS has been related to the presence of $\mathrm{MnS}$ initiation sites and aggressiveness in the pits. ${ }^{10-12}$ Furthermore, the thickness of the silica layer deposited on 304SS was much thinner than the thickness of the electrolyte estimated from $t_{\mathrm{b}}$, as mentioned above. Therefore, it is reasonable that the pitting potential of uncoated and silica-coated samples was independent of the silica layer thickness. The subsequent growth of pitting corrosion depends strongly on pit-solution chemistry. Because the silica layers deposited in this study were hydrophilic and took up water readily, the bulk solution had access to the 304SS surface through the open space in the layers. However, it seems that these layers created sufficient barriers for mass transport to influence pit growth, as evidenced by the slow decrease in OCP transients for silica-coated samples after initiation of pitting corrosion.

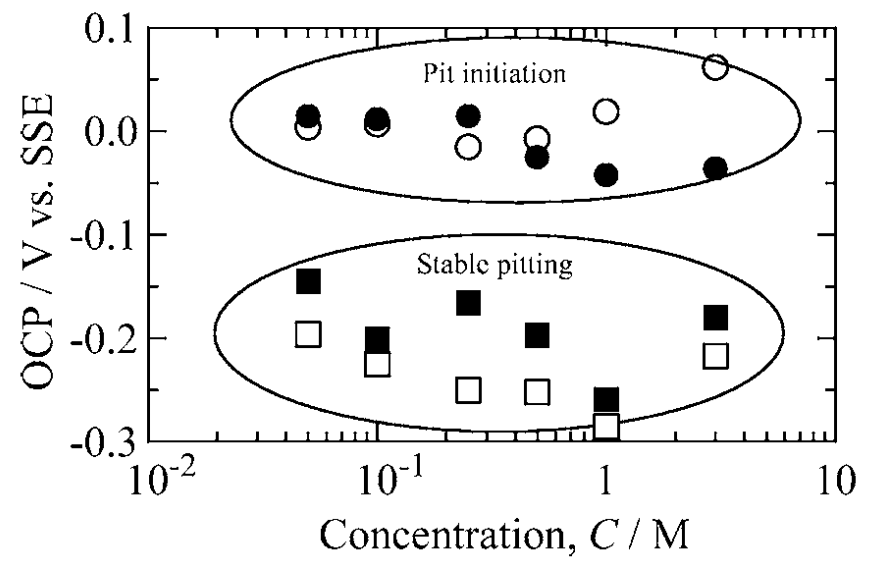

Figure 10. OCP before and after initiation of pitting corrosion for silica-coated and uncoated samples during drying of $x \mathrm{M} \mathrm{MgCl}_{2}$. Open and solid symbols denote the results for silica-coated and uncoated samples, respectively. The silica coating was deposited for $30 \mathrm{~s}$.

Assuming that pitting corrosion is initiated when the $\mathrm{Cl}$ - concentration of the electrolyte layer reaches $6 \mathrm{M}$, the electrolyte thickness when pitting corrosion initiates is less for a lower initial $\mathrm{MgCl}_{2}$ concentration in the electrolyte layer. Therefore, it should take longer for a lessconcentrated initial electrolyte layer to reach the critical chloride condition for pit initiation. However, this trend is not observed in Table II; $t_{b}$ seems to be independent of the initial concentration of the electrolyte layers. This is attributed to a dependence of the electrolyte evaporation rate on the electrolyte layer concentration; the evaporation rate is faster for lessconcentrated electrolyte layers. Therefore, in this case, $t_{\mathrm{b}}$ is not adequate to investigate the effect of the thickness of electrolyte on pit initiation. The OCP values just before initiation of pitting corrosion and the stable potentials during pitting corrosion were obtained from Fig. 6 and are plotted against the initial $\mathrm{MgCl}_{2}$ concentration in Fig. 10. The pitting potential seems to be 
independent of the initial $\mathrm{MgCl}_{2}$ concentration for values less than $0.5 \mathrm{M}$ for both coated and uncoated samples. However, for higher initial chloride concentrations, the pitting potential tends to increase with initial chloride concentration for uncoated samples and decrease with initial chloride concentration for coated samples. The stable OCP values after pit initiation for both silica-coated and uncoated samples decreases in the active direction with increasing initial $\mathrm{MgCl}_{2}$ concentration, except for the case of $3 \mathrm{M}$ electrolyte. Furthermore, the stable OCP values after initiation for the silica-coated samples are a little bit more noble than for the uncoated samples. A possible explanation is that anodic dissolution kinetics in the pits are inhibited for the silicacoated samples compared to uncoated samples and accelerated with increasing concentration of $\mathrm{MgCl}_{2}$.

Figure 11 shows optical images of the surface of a silica-coated 304SS after measurements of OCP transients in a saturated $0.5 \mathrm{M} \mathrm{MgCl}_{2}$ environment. In Fig. 11a, pitting corrosion can be observed through the silica layer on the sample. A dark spot exists in the center of the pitting corrosion site, and red rusting can be observed around the dark spot. Figure $11 \mathrm{~b}$ is a magnification of the dark spot seen through the silica layer. After removal of the silica layer, the pitting corrosion site appears clearly, as shown in Fig. 11c. The site is a large, shallow pit that contains a deep pit. Figure 12 shows pits in silica-coated and uncoated 304SS samples after drying of $\mathrm{MgCl}_{2}$ layers with different initial concentration. As seen in Fig. 12, it is unlikely that the silica layer works as a crevice former, because the pit morphology of the silica-coated samples is almost the same as that of the uncoated samples. The pit morphology seen in Fig. 12 is quite similar to the typical morphology of pits seen under atmospheric corrosion environments. ${ }^{6,9}$ However, the pit morphology depends on the initial $\mathrm{MgCl}_{2}$ concentration; the lower the $\mathrm{MgCl}_{2}$ concentration, the larger and shallower the pit formed. If the initial concentration of $\mathrm{MgCl}_{2}$ is low, the electrolyte layer is thin when the $\mathrm{Cl}$ - concentration reaches a critical value for initiation of pitting corrosion. In this case, large areas of the surface are activated and the surface is etched. In contrast, the electrolyte layer at the point of pit initiation was thicker for an initial concentration of $3 \mathrm{M}$, which resulted in smaller, deeper pits in both the uncoated and silica-coated samples. Therefore, it seems that the pit morphology depends more strongly on the electrolyte layer thickness than on the presence of a silica layer.

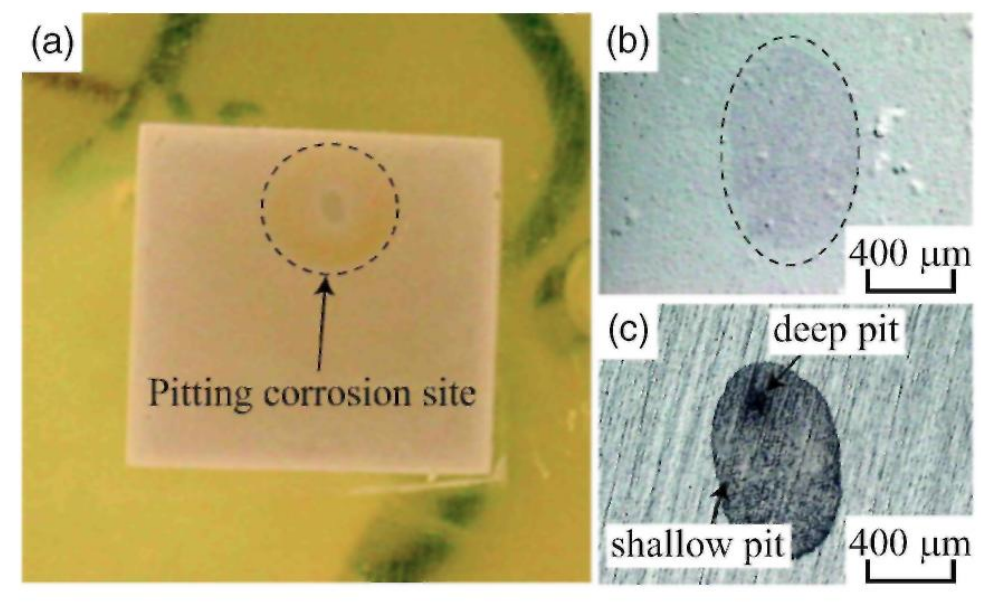

Figure 11. (Color online) Surface observation of a silica-coated 304SS after pitting corrosion took place during drying of $0.5 \mathrm{M} \mathrm{MgCl}_{2}$, (a) pitting corrosion site on the sample, (b) a shallow pit seen under the silica layer, and (c) the pit seen in $b$ after removal of the silica layer. A deeper pit was seen in the shallow pit. 

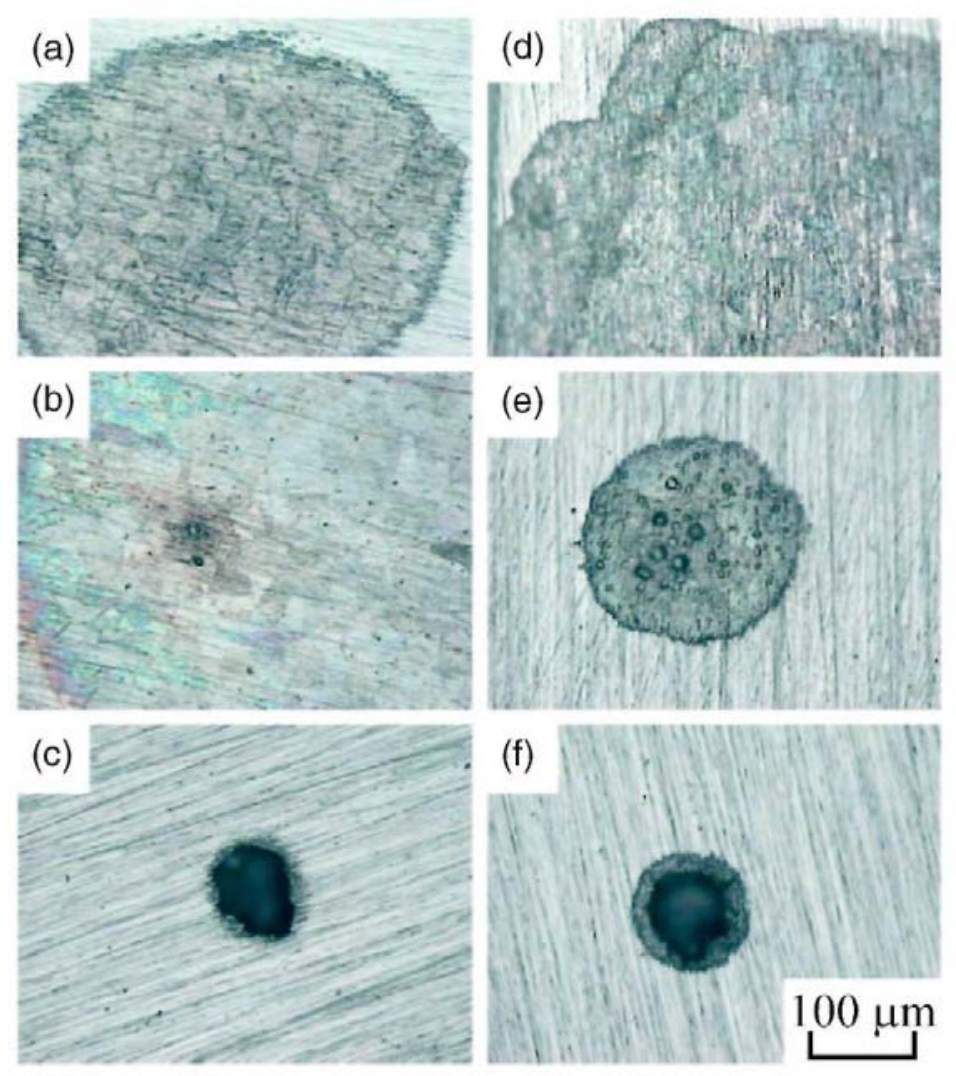

Figure 12. (Color online) Pit morphology for (a-c) uncoated and (d-f) silica-coated 304SS observed after OCP experiments with different concentrations of $\mathrm{MgCl}_{2}$, (a and d) $0.1 \mathrm{M}$, (b and e) $0.5 \mathrm{M}$, and (c and f) $3 \mathrm{M}$.

Effect of a silica layer on galvanic current transients. - Figure 7 shows the galvanic current transients with and without silica layers in environments with different humidities. In the low-humidity environment shown in Fig. 7a, the current transients initiated after 4-5 h and then vanished after about $1 \mathrm{~h}$. The sudden drop in current is interpreted as being caused by drying of the electrolyte layer because the time is similar to the time at which drying initiated noise in the OCP measurements in Fig. 5b. However, other explanations are possible. This experiment is a type of electrochemical noise measurement sensing the difference in behavior of two nominally identical electrodes. Only the net current is measured, reflecting the difference in reactions on the two electrodes. When localized corrosion is initiated on one electrode, the other becomes a net cathode and is protected to an extent. However, it is possible for localized corrosion on the second electrode to provide current balancing out the first electrode. Given the similarity in the transients in Fig. 7a and the similarity in time to the drying evidenced in Fig. 5b, this scenario seems less likely, and the cessation in current is attributed to drying. The time for drying is clearly increased by the presence of a silica layer.

The current transients took a different form in the higher humidity environment, as shown in Fig. 7b. In each case, initiation was accompanied by a relatively sharp current peak that reached a maximum within seconds. The current then decreased over a period of tens of seconds and then increased again, reaching a second peak after thousands of seconds. The current then slowly decreased again. This final current decrease was fastest for the thickest silica coating and 
slowest for the uncoated sample.

The sharp initial peak suggests that the high initial rates of dissolution associated with small pits could not be sustained under OCP conditions, probably because of a lack of sufficient cathodic current. The current decreased by about an order of magnitude and then slowly increased, perhaps as a result of an increase in pit area during growth. The total current after many hours of growth reached a value similar to that in the initial peak, which supports the notion that the current is limited by the cathodic reaction. The nominal current density is about 5 $\mu \mathrm{A} / \mathrm{cm}^{2}$, which is similar to ORR limiting current densities measured in concentrated chloride solutions. The final decrease in current might be associated with either an increase in ohmic potential drop or diffusion length associated with the growing pit or an eventual decrease in the available cathodic current.

\section{Conclusions}

In this study, the localized corrosion behavior of silica-coated 304SS was investigated in detail during drying of thin chloride-containing electrolyte layers in environments with different fixed relative humidity. The following conclusions can be drawn.

1. Silica layers deposited on 304SS by electrophoretic deposition absorbed electrolytes very well. Such samples can be utilized as a simulated particulate layer to investigate localized corrosion behavior for corrosion resistant alloys under atmospheric corrosion environments.

2. The OCP transients measured for silica-coated 304SS during drying of a thin electrolyte layer were similar to those for uncoated 304SS before initiation of pitting corrosion. However, after pit initiation the OCP decayed slower for coated samples than for uncoated samples. This result indicates that the silica layer did not affect the initiation of pitting corrosion but retarded the propagation of pitting corrosion.

3. Galvanic current transients were measured between coated and uncoated electrodes during drying of a layer of $0.5 \mathrm{M} \mathrm{MgCl}_{2}$ in an environment with humidity controlled by saturated $\mathrm{MgCl}_{2}$ environment. The galvanic current was affected by the presence of a silica layer; the final rate of current decrease was slower for silica-coated samples.

4. The pit morphology depended on the electrolyte layer thickness when pitting corrosion initiated and not on the presence of a silica layer.

5. There was no evidence that the silica layer acted as a crevice former. This might be because there is some spacing around silica particles and electrochemical reactions under a silica layer take place homogeneously.

\section{Acknowledgment}

The authors are grateful to Dr. R. Buchheit for fruitful discussions. Support by the Science and Technology Program of the Office of the Chief Scientist (OCS), Office of Civilian Radioactive Waste Management (OCRWM), U.S. Department of Energy (DOE), is gratefully acknowledged. The work was performed under the Corrosion and Materials Performance Cooperative, DOE Cooperative Agreement no. DE-FC28-04RW12252. The views, opinions, findings, and conclusions or recommendations of authors expressed herein do not necessarily state or reflect those of the DOE/OCRWM/ OCS.

The Ohio State University assisted in meeting the publication costs of this article. 


\section{References}

1. M. Apted, F. King, D. Langmuir, R. Arthur, and J. Kessler, J. Optim. Theory Appl., 18, 43 (2005).

2. E. Tada and G. S. Frankel, J. Electrochem. Soc, 154, C312 (2007).

3. A. R. Boccaccini, J. A. Roether, B. J. C. Thomas, M. S. P. Shaffer, E. Chavez, E. Stoll, and E. J. Minay, J. Ceram. Soc. Jpn., 114, 1 (2006).

4. I. Zhitomirsky, Adv. Colloid Interface Sci., 97, 279 (2002).

5. O. O. Van der Biest, Annu. Rev. Mater. Sci., 29, 327 (1999).

6. R. P. Vera Cruz, A. Nishikata, and T. Tsuru, Corros. Sci., 40, 125 (1998).

7. D. A. Jones, Principles and Prevention of Corrosion, 2nd ed., Prentice Hall, Upper Saddle River, NJ (1996).

8. D. W. Rice and P. Peterson, J. Electrochem. Soc, 128, 1619 (1981).

9. Y. Tsutsumi, A. Nishikata, and T. Tsuru, J. Electrochem. Soc, 152, B358 (2005).

10. G. S. Frankel, L. Stockert, F Hunkeler, and H. Böhni, Corrosion (Houston), 43, 429 (1987).

11. P. C. Pistorius and G. T. Burstein, Corros. Sci., 33, 1885 (1992).

12. G. T. Burstein, P. C. Pistorius, and S. P. Mattin, Corros. Sci., 35, 57 (1993). 